\title{
Al in Healthcare practice: opportunities and challenges for clinical decision support systems
}

\author{
David R. Millen \\ IBM Watson Health \\ david_r_millen@us.ibm.com
}

\begin{abstract}
In the past few years there has been great optimism about the potential benefits of incorporating AI (cognitive) capabilities into healthcare products and services. Indeed, progress in Natural Language Processing (NLP) has made electronic health records both more accessible and comprehensible, advances in image processing algorithms has helped to early identify tumors, and large datasets with new discovery services can help with breakthrough insights in life sciences and drug discovery. Importantly, new AIbased solutions are embedded in the sociotechnical systems of clinical care and within complex regulatory environments and globally diverse cultural frameworks. In this talk, I will present several case studies of novel AI based healthcare applications that have been introduced in recent years and share lessons learned along the way. Particular focus will be on design research challenges for healthcare products, including understanding complex workflows within clinical settings and highly specialized and diverse mental modals, and understanding multiple stakeholders and interdependent participants. Design considerations and emerging opportunities for AI-based clinical decision support systems will also be shared.
\end{abstract}

Keywords

Artificial Intelligence, Healthcare, Clinical Decision

\section{SHORT-BIO}

David Millen is the Senior Design Research Manager at Watson Health in Cambridge, MA. His group provides design research for new products in healthcare segments that include Oncology, Life Sciences, Care Management, and Government social programs. Prior to joining IBM,

\footnotetext{
Permission to reproduce or distribute, in whole or in part, material extracted from this work, verbatim, adapted or remixed, as well as the creation or production from the content of such work, is granted without fee for non-commercial use, provided that the original work is properly credited.

IHC 2019 - Plenárias, Outubro 21-25, 2019, Vitória, Brasil. In Anais Estendidos do XVIII Simpósio Brasileiro sobre Fatores Humanos em Sistemas Computacionais. Porto Alegre: SBC.

(C)2019 by the author(s), in accordance with the terms of the Creative Commons Attribution-NonCommercial 4.0 International Public License (CC BY-NC 4.0)
}

David worked at AT\&T Research and Bell Laboratories, where he explored how new technologies changed employee work activities, organizational roles, and patterns of communication. He also directed a User Interface Design Group, which was responsible for the user interface design of advanced business communications systems as well as conducting exploratory prototype development of advanced speech applications and pen-based interfaces. David has been an adjunct faculty member at Rutgers University (NJ) and at Tufts University (MA), where he recently taught a class on The Social Web. David holds a BA from Columbia University, an MS in Management from Purdue University and a PhD. in Cognitive Science/Psychology from Rutgers University. In 2011, David was recognized by ACM as a Distinguished Scientist for his work in the area of social computing.

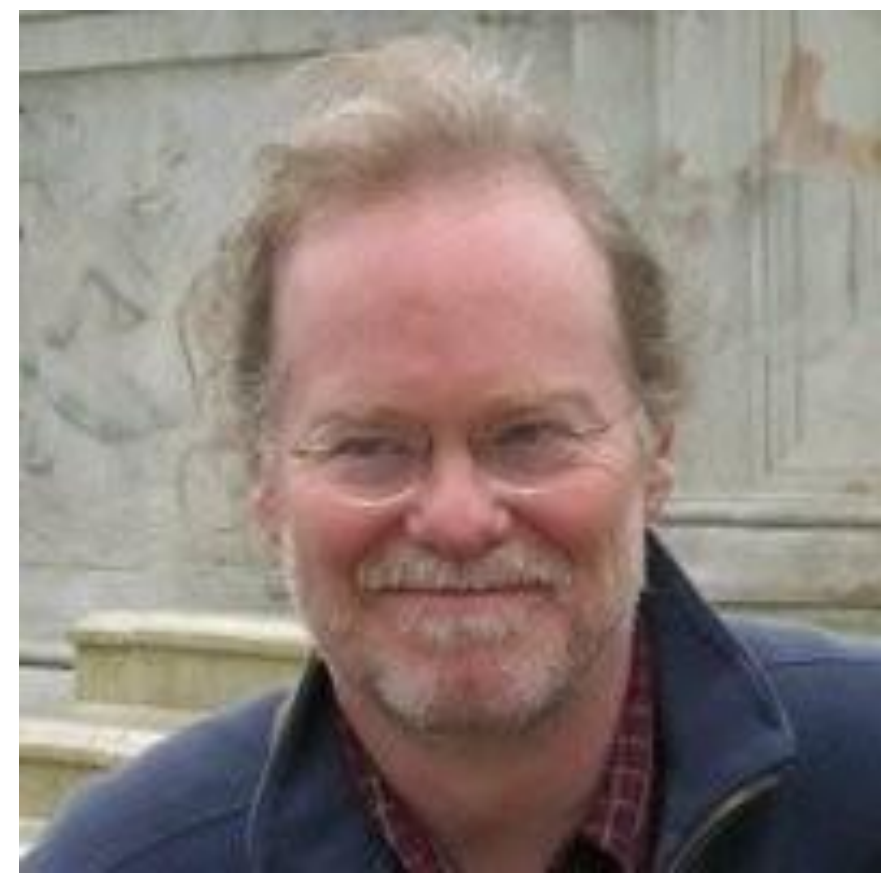

Figure 1. David Millen 